\title{
QUALIDADE DE DIÁSPOROS DE Myracrodruon urundeuva Fr. All. ARMAZENADOS SOB DIFERENTES CONDIÇÕES ${ }^{1}$
}

\author{
SIDNEY FERNANDO CALDEIRA², SONIA CRISTINA JULIANO GUALTIERI DE ANDRADE PEREZ ${ }^{3}$
}

\begin{abstract}
RESUMO - Este trabalho teve por objetivo avaliar a qualidade fisiológica de diásporos de aroeira acondicionados em diferentes embalagens e armazenados em dois ambientes. Diásporos acondicionados em embalagem de lata e em sacos de polietileno, de papel e de malha de polietileno foram armazenados em câmara refrigerada por um condicionador de ar e em ambiente de sala. Após seis, 12, 18, 24 e 30 meses de armazenamento os diásporos foram avaliados pela germinação sobre papel e sobre areia, em laboratório, e pela emergência em areia e em substrato comercial, em casa de vegetação. Independentemente da embalagem, os diásporos armazenados em câmara até 30 meses mantiveram a viabilidade (54\% a $73 \%$ ) quando avaliados pela germinação sobre papel. Germinados sobre areia, a viabilidade se manteve até 18 meses em todas as embalagens; até 24 meses em lata e até 30 meses em saco de polietileno. O vigor foi mantido por seis meses com o uso de qualquer embalagem, detectado pela emergência em areia ( $56 \%$ a $65 \%$ ) e em substrato comercial (67\% a $75 \%$ ). A partir deste período, o vigor diminuiu gradativamente até 30 meses, em menor intensidade para os diásporos mantidos em lata (46\%) e em saco de polietileno (45\%), em relação ao saco de papel (32\%) e de malha (28\%). Em ambiente de sala, com qualquer embalagem de acondicionamento, a germinação e o vigor foram reduzidos após seis meses de armazenamento, mas em menor intensidade para os diásporos mantidos em lata e em saco de polietileno. Após 12 meses de armazenamento a deterioração dos diásporos aumentou e após 18 meses foi completa. Durante o armazenamento, o substrato afetou a germinação, mas não afetou o vigor. O teste de condutividade elétrica e a massa de mil diásporos não foram adequados para avaliar a qualidade fisiológica dos diásporos de aroeira durante o armazenamento.
\end{abstract}

Termos para indexação: aroeira, condutividade elétrica, massa de mil diásporos, germinação, vigor.

\section{QUALITY OF Myracrodruon urundeuva Fr. All. DIASPORAS STORED UNDER DIFFERENT CONDITIONS}

\begin{abstract}
This work had to objective to evaluate the physiological quality of Myracrodruon urundeuva diasporas conditioned in different packs and stored under two conditions. The diasporas conditioned in a can and bags of polyethylene, of paper, and of mesh polyethylene were stored in chamber cooled by air conditioner and in room environment. After six, 12, 18, 24 and 30 months of storage the diasporas were evaluated by the germination on paper and on sand and for the emergence in sand and commercial substratum in the greenhouse. Diasporas stored up to 30 months in chamber with air conditioning, independent of the container, kept the viability ( $54 \%$ to $73 \%$ ), evaluated by the germination on paper. When germinated on sand, the viability was kept up to 18 months in all the containers, up to 24 months for the can and up to 30 months for the polyethylene bag. With either
\end{abstract}

${ }^{1}$ Submetido em 05/09/2007. Aceito para publicação em 09/09/2008. Parte da Tese de Doutorado do primeiro autor apresentada ao PPG em Ecologia e Recursos Naturais da UFSCar.

${ }^{2}$ Engenheiro Florestal, M.Sc., Professor Adjunto, Departamento de Engenharia Florestal, UFMT, Avenida Fernando Correa da Costa s/n,
Coxipó, CEP: 78068-008, Cuiabá, MT, sidcal@ufmt.br.

${ }^{3}$ Bióloga, Doutora, Professora Adjunta, Departamento de Botânica, UFSCar, Via Washington Luiz, km 235, Caixa Postal 676, CEP: 13565905, São Carlos, SP, dscp@power.ufscar.br. 
container, the vigor was kept up to six months, detected by the emergency in sand (56\% to $65 \%)$ and commercial substratum (67\% a 75\%). From this point on, it diminished gradually up to 30 months, in lesser intensity for those kept in can $(46 \%)$ and in polyethylene bag $(45 \%)$, in relation to the paper $(32 \%)$ and mesh (28\%) bags. In room environment, at the age of six months, with any container, the germination and the vigor were reduced, but in lesser intensity for the diasporas kept in can, and in polyethylene bag. At the age of 12 months the deterioration increased and the age of 18 months it was complete. During the storage, the substratum affected the germination, but it did not affect the vigor. The test of electric conductivity and the mass of a thousand diasporas were not adequate to evaluate the physiological quality during storage.

Index terms: electrical conductivity, germination, thousand mass diasporas, vigor.

\section{INTRODUÇÃO}

A principal demanda por sementes de espécies florestais nativas está ligada à produção de mudas para reflorestamento ambiental, com destaque para as espécies endêmicas e aquelas que ocorrem em biomas sob grande ação antrópica. Para espécies com valor comercial, a ação é mais intensa, como ocorre com a aroeira que se encontra sob risco de extinção (Abdala et al., 2002).

A utilização de frutos como diásporos é comum em espécies florestais e, no caso da aroeira, além da dificuldade de extração, a germinação das sementes apresenta valores inferiores em relação aos obtidos com seus frutos (Duarte et al., 2000). Os diásporos coletados com menor teor de água germinam melhor em relação àqueles com maior teor de água (Siqueira e Figliolia, 1987), com uma relação logarítima negativa entre o teor de água e a longevidade (Medeiros et al., 1998), e são ortodoxos, com potencial para armazenamento (Medeiros e Cavallari, 1992; Medeiros et al., 1998; 2000). Ainda assim, informações sobre a sua qualidade inicial são raras (Dorneles et al., 2005).

A germinação das sementes da aroeira tem sido feita nos substratos sobre papel de filtro (Souza et al., 1980; Medeiros e Cavallari, 1992; Frayha, 1999; Silva et al., 2002), rolo de papel toalha (Martins Netto e Faiad, 1995; Salomão e Allem, 2001; Teófilo et al., 2004), ágar-ágar a 1\% (Medeiros et al., 2000) e vermiculita (Duarte et al., 2000; Dorneles et al., 2005). Pacheco et al. (2006) não encontraram diferença na germinação entre e sobre papel mata-borrão, areia, vermiculita e fibra de coco, sob diferentes temperaturas.

O teste de condutividade elétrica dos lixiviados tem sido utilizado para avaliação de diásporos de aroeira armazenados (Duarte et al., 2000). Este teste é indireto e considerado rápido, em relação ao teste de germinação (Piña-Rodrigues et al., 2004); porém, recente com espécies florestais, necessitando a sua adequação (Thapliyal e Connor, 1997; Santos e Paula,
2005; Pontes et al., 2006). Também já foi utilizado para avaliar a qualidade de sementes no armazenamento, e efeitos do condicionamento osmótico e do estresse salino e térmico em sementes de Chorisia speciosa (Perez e Jardim, 2005).

Além do fator genético, a manutenção da viabilidade da semente depende, dentre outros fatores, do seu teor de água, da embalagem e da temperatura durante o armazenamento, do estádio de maturação e da sua qualidade inicial (Carneiro e Aguiar, 1993; Phartyal et al., 2002; Baudet e Villela, 2005; Marcos Filho, 2005), da estrutura, tamanho e densidade da semente (Carneiro e Aguiar, 1993; Baudet e Villela, 2005), da sanidade das sementes (Baudet e Villela, 2005; Marcos Filho, 2005), do grau de dormência e ecofisiologia da germinação (Phartyal et al., 2002) e do vigor das árvores matrizes (Carneiro e Aguiar, 1993).

O armazenamento ainda possibilita alguma independência do período de disponibilidade natural e da quantidade de produção anual das espécies florestais. Com diásporos de aroeira foram testadas embalagens como sacos de polietileno, de algodão e de alumínio (Souza et al., 1980), de filó (Medeiros e Cavallari, 1992), de papel trifoliado, de alumínio e de polietileno (Medeiros et al., 2000), de papel multifoliado e garrafa de polietileno (Teófilo et al., 2004), em ambientes de baixa temperatura, câmara seca, ou a sua combinação (Souza et al., 1980; Frayha, 1999; Teófilo et al., 2004) ou ultras-baixas temperaturas (Medeiros e Cavallari, 1992; Medeiros et al., 2000). Contudo, nesses trabalhos o período de armazenamento foi curto, em torno de 12 meses.

Isto posto, o objetivo deste trabalho foi o de avaliar a qualidade fisiológica de diásporos de aroeira acondicionados em diferentes embalagens e armazenados em dois ambientes.

\section{MATERIAL E MÉTODOS}

O trabalho foi conduzido com diásporos de aroeira 
coletados manualmente de 61 matrizes, em setembro de 2003, selecionadas tomando por base o seu aspecto vigoroso, relacionado com a condição fitossanitária e com a ausência de defeitos na copa e no fuste das árvores. A área de coleta de sementes está localizada em Cuiabá, MT, em um paralelogramo formado pelas coordenadas $15^{\circ} 21^{\prime} 58^{\prime \prime} \mathrm{S}$, $56^{\circ} 12^{\prime} 39^{\prime \prime} \mathrm{W}$ e $15^{\circ} 22^{\prime} 17^{\prime \prime} \mathrm{S}, 56^{\circ} 12^{\prime} 14^{\prime \prime} \mathrm{W}$. A região apresenta valores médios de $25,7^{\circ} \mathrm{C}$ de temperatura, $74 \%$ de umidade relativa e precipitação de $1450 \mathrm{~mm} \cdot \mathrm{ano}^{-1}$. O solo é do tipo Litólico Álico, de textura muito cascalhenta e relevo ondulado com afloramento de rocha calcária.

Os diásporos beneficiados e homogeneizados com um "divisor de solos" (Brasil, 1992) foram acondicionados em lata hermética e em sacos de polietileno transparente, espessura de $0,15 \mathrm{~mm}$; de papel Kraft, espessura de $0,25 \mathrm{~mm}$; e de malha de polietileno, com formato hexagonal de $2 \mathrm{~mm}$. Em seguida, foram armazenados em câmara controlada com um condicionador de ar e um desumidificador $\left(19,1^{\circ} \mathrm{C} \pm 1,3^{\circ} \mathrm{C}\right.$ e UR de $70,5 \% \pm 6,5 \%)$ e em ambiente de sala $\left(27,7^{\circ} \mathrm{C} \pm 1,6^{\circ} \mathrm{C}\right.$ e $63,1 \% \pm 9,1 \%$ de UR), sendo que as médias compensadas foram obtidas com termohigrógrafos.

Qualidade durante o armazenamento - após seis, 12, 18,24 e 30 meses de armazenamento, os diásporos foram avaliados pelos parâmetros descritos a seguir.

Teor de água - expresso em base úmida foi determinado em quatro amostras de cerca de $4 \mathrm{~g}$ de diásporos, em estufa a $105^{\circ} \mathrm{C} \pm 3^{\circ} \mathrm{C}$, durante 24 horas (Brasil, 1992).

Germinação - em caixas de plástico transparente de 11 x 11 x $3 \mathrm{~cm}$, com tampa, foram depositados 25 diásporos, em quatro repetições, para germinação sobre duas folhas de papel mata-borrão e sobre areia esterilizada. O papel foi umedecido até o máximo de saturação e a areia a $60 \%$ da capacidade de campo. Cada caixa foi envolvida com uma película de filme de PVC transparente e depositada em câmaras de germinação Fanem modelo $347-\mathrm{CDG}$, a $25^{\circ} \mathrm{C}$, fotoperíodo de oito horas. Vigor - em casa de vegetação, foram semeados quatro repetições de 50 diásporos para emergência entre areia esterilizada e entre substrato comercial Plantmax ${ }^{\circledR}$. A profundidade de semeadura foi entre 0,5 a $1,0 \mathrm{~cm}$. Para o substrato areia, foram usadas bandejas com $29 \times 39 \times 7 \mathrm{~cm}$ e para o substrato comercial, tubetes de plástico rígido com capacidade para $175 \mathrm{~cm}^{3}$. Nas duas condições foram efetuados registros diários do número de diásporos com cotilédones expandidos e normais, até o $10^{\circ}$ dia, que foi o critério utilizado para avaliar tanto a germinação como o vigor, pelo interesse na produção de mudas. Condutividade elétrica- em balança analítica foram pesadas quatro repetições de 50 diásporos e colocadas em copos de plástico com capacidade para $200 \mathrm{~mL}$, contendo $75 \mathrm{~mL}$ de água deionizada. Os conjuntos foram depositados em câmara de germinação a $25^{\circ} \mathrm{C}$, por 24 horas no escuro. A leitura dos lixiviados foi efetuada em condutivímetro "Digimed" modelo CD-20; os valores das leituras foram divididos pela massa dos diásporos, e expressos em $\mu \mathrm{S} . \mathrm{cm}^{-}$ ${ }^{1} \cdot \mathrm{g}^{-1}$ (Vieira e Krzyzanowski, 1999). Massa de mil diásporos - em balança analítica, foram pesadas oito repetições de 100 diásporos e os resultados foram expressos para mil diásporos (Brasil, 1992).

$\mathrm{O}$ delineamento experimental foi $\mathrm{o}$ inteiramente casualizado em esquema fatorial de $4 \times 2 \times 5$ (embalagem, ambiente e período de armazenamento). As variáveis utilizadas foram germinação (porcentagem dos diásporos com cotilédones expandidos e normais sobre papel e sobre areia) e vigor (porcentagem de emergência entre areia e substrato comercial). Os resultados foram submetidos aos testes de normalidade e de homocedasticidade e as médias dos tratamentos foram comparadas pelo teste de ScottKnott a 5\%. Quando os dados originais e transformados não atenderam a esses pressupostos, foi utilizada a análise multivariada, através do método hierárquico aglomerativo do vizinho mais distante, e a distância Euclidiana foi utilizada para a ligação entre os grupos (Dal'Col Lucio et al., 2006). Foram construídos quartís (Sautu et al., 2006) para interpretar os efeitos dos fatores isolados da embalagem, do ambiente e do período de armazenamento. A correlação entre as variáveis foi baseada nos coeficientes de Kendall Tau, que foram adjetivados com a padronização citada por Dorneles et al. (2005). Para as análises estatísticas foram utilizados os programas SISVAR ${ }^{\circledR}$ (Ferreira, 2000) e o SPSS.

\section{RESULTADOS E DISCUSSÃO}

O teor de água inicial de $9,7 \%$ foi semelhante aos obtidos por Martins Neto e Faiad (1995) e por Souza et al. (1980). A variação do teor de água durante o armazenamento foi semelhante nos diásporos acondicionados em lata hermética e em saco de polietileno, independentemente do ambiente, com menores trocas de vapor $\mathrm{d}$ água. Os diásporos mantidos em sacos de papel e de malha apresentaram maiores variações nessas trocas e comportamento distinto em cada ambiente (Figura 1). Souza et al. (1980) constataram que os recipientes herméticos não evitaram flutuações no teor de água de diásporos de aroeira, mas que estas variações foram menores com o recipiente de alumínio em câmara fria. No ambiente controlado, independentemente do valor médio $\left(19,1^{\circ} \mathrm{C}\right.$ e $70,5 \%$ de UR), a temperatura variou entre 
14,0 a $24,5^{\circ} \mathrm{C}$ e a umidade relativa entre 51,6 a $88,0 \%$, indicando baixa precisão do termostato o que não garantiu um bom controle destas condições. No ambiente de sala essa variação foi de 23,1 a $31,0^{\circ} \mathrm{C}$ e de 38,0 a $87,6 \%$ de umidade relativa, respectivamente. Nesse ambiente, o teor de água dos diásporos acondicionados em sacos de papel

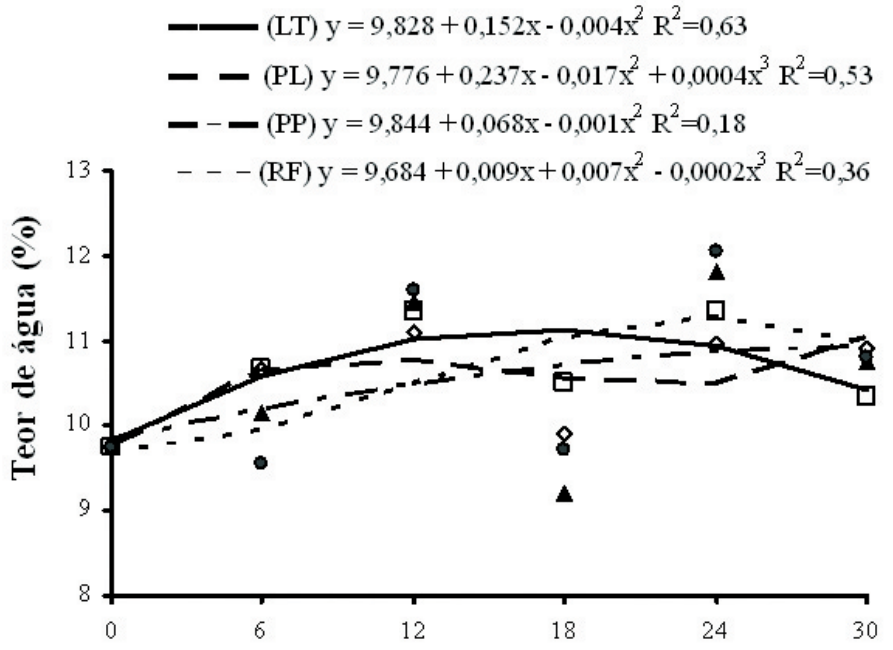

(A)

Período de armazenamento e de malha aumentou após seis meses e diminuiu após 12 meses de armazenamento. Após 18 meses, o teor de água foi semelhante para todas as embalagens, provavelmente em razão da perda de viabilidade dos diásporos. Na câmara controlada aumentou após 12 meses. Teófilo et al. (2004) registraram oscilações semelhantes.

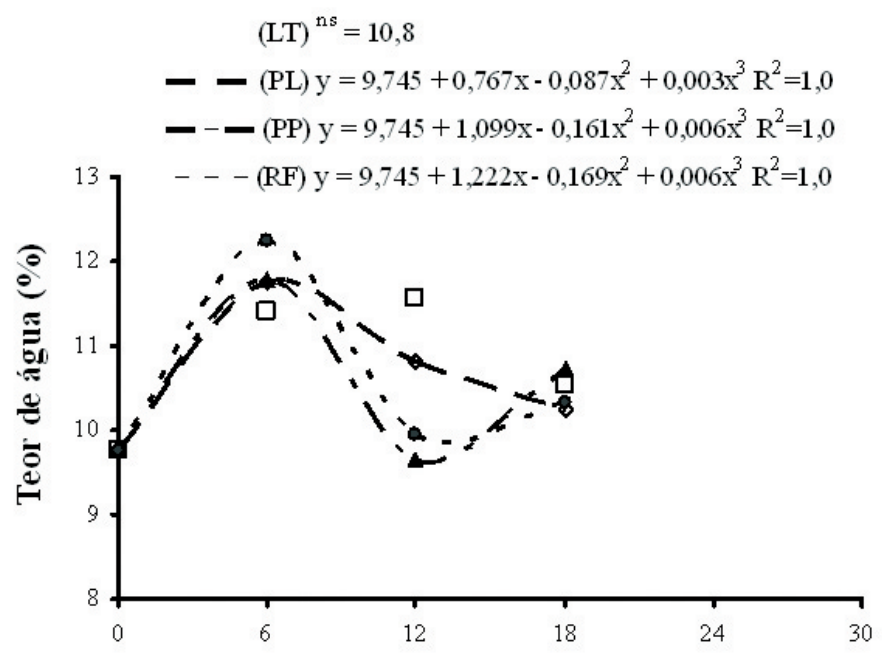

B

Período de armazenamento

FIGURA 1. Teor de água de diásporos de Myracrodruon urundeuva acondicionados em lata (LT, $\square$ ) e em sacos de polietileno $(\mathrm{PL}, \diamond)$, de papel $(\mathrm{PP}, \Delta)$, e de malha $(\mathrm{RF}, \bullet)$ em função do período de armazenamento em câmara controlada (A) e em ambiente de sala (B). (ns) regressão não significativa. Cuiabá, MT, 20032006.

Com relação à germinação e vigor, o critério utilizado para obtenção dos grupos, com o uso do método hierárquico aglomerativo, foi equivalente ao valor máximo de $19 \%$ da variável analisada. $\mathrm{O}$ total de tratamentos para cada ambiente de armazenamento e a respectiva faixa de germinação e de vigor, para cada um dos grupos formados, são apresentados na Tabela 1.

TABELA 1. Número de tratamentos semelhantes pela análise de agrupamento de diásporos de Myracrodruon urundeuva armazenados em câmara controlada (CC) e em ambiente de sala (SL), e as faixas de germinação (G) e de vigor (V), nos respectivos substratos. Cuiabá, MT, 2003-2006.

\begin{tabular}{|c|c|c|c|c|c|c|c|c|c|c|c|c|}
\hline \multirow{3}{*}{ Grupo } & \multicolumn{6}{|c|}{ Germinação } & \multicolumn{6}{|c|}{ Vigor } \\
\hline & \multicolumn{3}{|c|}{ Sobre papel } & \multicolumn{3}{|c|}{ Sobre areia } & \multicolumn{3}{|c|}{ Areia } & \multicolumn{3}{|c|}{ Plantmax ${ }^{\circledR}$} \\
\hline & $\mathrm{CC}$ & SL & $\mathrm{G}(\%)$ & $\mathrm{CC}$ & SL & $\mathrm{G}(\%)$ & $\mathrm{CC}$ & SL & $\mathrm{V}(\%)$ & $\mathrm{CC}$ & SL & $\mathrm{V}(\%)$ \\
\hline 1 & $21 *$ & 1 & 54 a 73 & $16^{*}$ & 0 & 52 a 68 & $8 *$ & 0 & 56 a 65 & $5^{*}$ & 0 & 67 a 75 \\
\hline 2 & 0 & 5 & 14 a 29 & 4 & 1 & 34 a 48 & 10 & 1 & 35 a 51 & 11 & 0 & 44 a 63 \\
\hline 3 & 0 & 6 & 0 a 8 & 1 & 1 & 23 e 29 & 2 & 1 & 23 a 28 & 5 & 2 & 24 a 38 \\
\hline 4 & - & - & - & 0 & 10 & 0 e 16 & 1 & 10 & 0 a 16 & 0 & 10 & 0 a 13 \\
\hline
\end{tabular}

(*) grupo onde foi incluída a condição inicial dos diásporos.

Independentemente do substrato utilizado, os resultados iniciais foram sempre enquadrados no primeiro grupo, indicando que os outros tratamentos incluídos nesse grupo são semelhantes. A germinação e o vigor iniciais foram 
mantidos para os diásporos armazenados em câmara controlada, respectivamente até 24 e seis meses, com algumas embalagens, exceto na avaliação da germinação sobre papel. Independentemente da embalagem, os diásporos mantidos em ambiente de sala perderam rapidamente a viabilidade e o vigor iniciais após seis meses de armazenamento.

Sobre papel, os diásporos acondicionados em lata hermética e mantidos no ambiente de sala até seis meses, conservaram a germinação inicial, e aqueles acondicionados em outras embalagens tiveram a germinação reduzida para 14 a 29\%. Após 12 meses a deterioração aumentou e após 18 meses foi completa. $\mathrm{O}$ uso da areia detectou diferenças de germinação entre os tratamentos mantidos em ambiente controlado. Assim, não mantiveram a germinação inicial os diásporos acondicionados em malha até 24 meses e nas outras embalagens até 30 meses. Também foi menor a germinação dos diásporos acondicionados em lata e mantidos em ambiente de sala por seis meses.

A perda do vigor inicial foi detectada tanto na emergência entre areia como no substrato Plantmax ${ }^{\circledR}$ para os diásporos mantidos em ambiente de sala, independentemente da embalagem e do período armazenamento. Por outro lado, os diásporos de alguns tratamentos mantidos em câmara controlada mantiveram o vigor inicial. Assim, os tratamentos que mantiveram o vigor inicial, analisados com os dois substratos, foram os diásporos armazenados até seis meses em câmara controlada, independentemente da embalagem de acondicionamento.

Para o fator embalagem (Figura 2), exceto a análise da germinação sobre papel, as medianas apresentaram valores decrescentes com o aumento da permeabilidade do material. Isso indica que os substratos expressaram resultados diferentes na análise da germinação, e isto não ocorreu com o vigor. Foi observada diminuição na faixa dos valores do primeiro quartil, de 0 a $40 \%$, para 0 a $8 \%$, de acordo com o aumento da permeabilidade das embalagens, sendo a maior faixa obtida com a análise da germinação sobre papel, 0 a $18 \%$, o que deve ser atribuído mais ao efeito do ambiente de sala do que da embalagem. No último quartil, a faixa de valores mínimos, em torno de $60 \%$, diminuiu até cerca de $40 \%$ para a embalagem permeável na análise da emergência em areia. Ainda assim, o valor máximo oscilou em torno de $60 \%$ o que pode ser atribuído aos resultados obtidos no ambiente de câmara controlada.

Para o ambiente de armazenamento (Figura 2), os valores estão acima de $30 \%$ na câmara controlada e abaixo deste valor no ambiente de sala; neste, as medianas estão próximas ou agrupadas ao valor zero. $\mathrm{Na}$ análise de germinação sobre papel ocorreu menor amplitude de resultados, 54 a 73\%, comparada com a areia, 34 a $68 \%$. O valor mínimo de $28 \%$ de emergência foi semelhante para os dois substratos, enquanto o valor máximo foi de $75 \%$ em substrato comercial e de $65 \%$ em areia. Outro aspecto a destacar é relativo aos valores dispersos observados em todas as análises para os diásporos acondicionados em lata e armazenados em ambiente de sala durante seis meses, além da emergência em areia dos diásporos acondicionados em saco de polietileno. Nestes casos, o resultado reflete o efeito positivo das embalagens na conservação da qualidade dos diásporos armazenados na sala. Por outro lado, a germinação em areia dos diásporos acondicionados em saco de malha e armazenados por 30 meses em câmara controlada, reflete o efeito negativo desta embalagem na conservação dos diásporos em relação às outras embalagens.

A redução na germinação das sementes no ambiente de sala está relacionada com a variação no teor de água e a maior temperatura, que aumentam a atividade respiratória e reduz a qualidade dos diásporos, como conseqüência da diminuição ou esgotamento de suas reservas (Carneiro e Aguiar, 1993). A temperatura afeta diretamente a velocidade das reações químicas, acelerando a respiração e o desenvolvimento de microrganismos; assim, a sua redução beneficia a conservação de sementes ortodoxas (Marcos Filho, 2005). O armazenamento na câmara controlada (em torno de $19,1^{\circ} \mathrm{C}$ ) proporcionou germinação acima de $52 \%$, enquanto que no ambiente de sala (em torno de $27,7^{\circ} \mathrm{C}$ ) os melhores resultados ficaram abaixo de $46 \%$, com diferenças entre as formas de análise.

Para o período de armazenamento (Figura 2), as medianas entre 50 e $60 \%$ após seis meses decresceram para 20 a 30\% após 18 meses e após 24 e 30 meses apresentaram valores em torno de $40 \%$. Como a deterioração não é reversível, este resultado é decorrente da não avaliação dos diásporos armazenados no ambiente de sala nos dois últimos períodos de armazenamento. Com a diminuição dos valores de germinação e vigor, o quartil inferior diminuiu gradualmente até formar uma única linha aos 18 meses. Assim, após 24 e 30 meses apenas apresentaram germinação e vigor os diásporos armazenados em câmara controlada, quando a germinação sobre papel proporcionou resultados similares e de pouca amplitude, nos dois períodos, enquanto que a germinação sobre areia diferenciou melhor a perda de viabilidade dos diásporos após 30 meses. A germinação e o vigor dos diásporos de aroeira diminuíram com o tempo, nos dois substratos utilizados, e a redução foi superior à registrada por Souza et al. (1980) e Teófilo et al. (2004). 

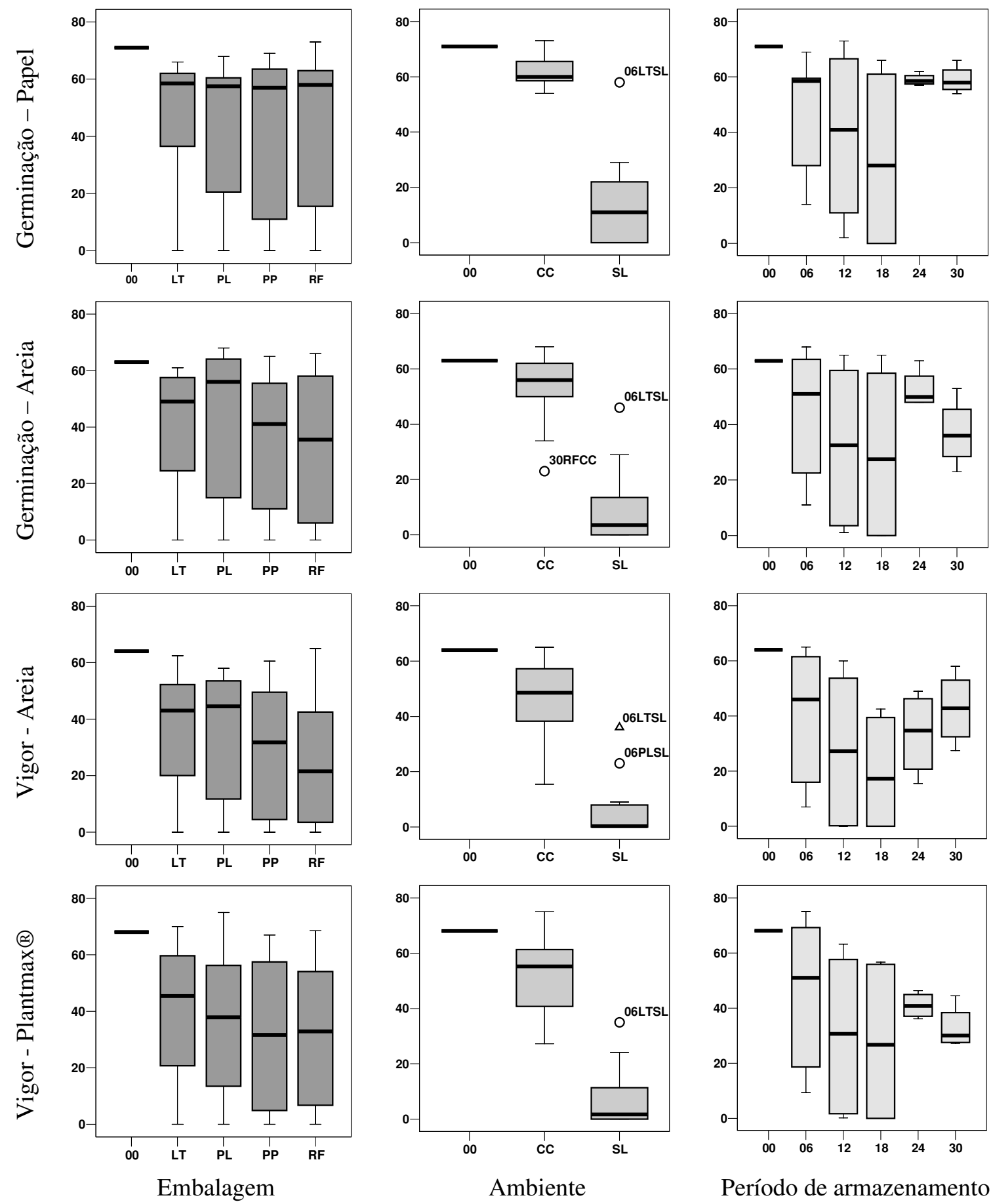

FIGURA 2. Diagrama de caixas com mediana, quartís, dispersos $(\circ)$, e extremos $(\Delta)$ da germinação e vigor de diásporos de Myracrodruon urundeuva, nos respectivos substratos, em função da embalagem (LT = lata; PL, PP e RF, respectivamente, sacos de polietileno, de papel, e de malha); do ambiente (CC = câmara controlada e $\mathrm{SL}=$ ambiente de sala) e do período (meses) de armazenamento. A barra isolada é o valor inicial. Cuiabá, MT, 2003-2006.

Na germinação sobre papel, algumas vezes a radícula não se fixou no substrato e houve dificuldade na liberação dos cotilédones. Esse fato não aconteceu na areia, que reteve o exocarpo. Contudo, Pacheco et al. (2006) não encontraram diferença entre esse e outros substratos para germinação da aroeira. Quanto ao substrato comercial, apesar de apresentar 
densidade inferior à da areia, possui a vermiculita que pode reter a água por mais tempo. A menor variação do teor de água nesse substrato poderia facilitar a absorção de água pelos diásporos depositados nos tubetes e favorecer a emergência, ainda que as regas tenham sido homogêneas.

Os coeficientes de correlação (Tabela 2) foram significativos e positivos, e adjetivados como muito altos, entre os resultados da germinação sobre areia com a emergência entre areia e no substrato comercial. Isto também ocorreu com a emergência entre areia e entre Plantmax ${ }^{\circledR}$, em casa de vegetação. As correlações entre a germinação sobre papel com a germinação sobre areia e com a emergência nos dois substratos foram adjetivadas como substanciais. Os resultados coadunam com o observado por Marques et al. (2002) que discriminaram de modo eficiente três lotes de sementes de Dalbergia nigra, além de alta correlação entre os resultados de laboratório e de viveiro.

TABELA 2. Coeficiente de correlação simples de Kendall Tau entre a germinação sobre papel (SP) e sobre areia (SA), a emergência em areia (EA) e em substrato comercial (ES), a condutividade elétrica (CE) e a massa de mil diásporos (MM) de Myracrodruon urundeuva armazenados sob diferentes condições. Cuiabá, MT, 2003-2006.

\begin{tabular}{cccccc}
\hline \multicolumn{7}{c}{ SP } & SA & EA & ES & CE \\
\hline SA & $0,62 * *(\mathrm{SB})$ & & & & \\
EA & $0,65^{* *}(\mathrm{SB})$ & $0,72 * *(\mathrm{MA})$ & & & \\
ES & $0,69 * *(\mathrm{SB})$ & $0,83 * *(\mathrm{MA})$ & $0,77 * *(\mathrm{MA})$ & & \\
CE & $-0,15(\mathrm{BX})$ & $-0,11(\mathrm{BX})$ & $-0,09(\mathrm{NG})$ & $-0,09(\mathrm{NG})$ & \\
MM & $0,19(\mathrm{BX})$ & $0,17(\mathrm{BX})$ & $0,18(\mathrm{BX})$ & $0,15(\mathrm{BX})$ & $-0,18(\mathrm{BX})$ \\
\hline
\end{tabular}

$* \mathrm{P}<0,05 ; * * \mathrm{P}<0,01$. NG: negligenciável $(0,001$ a 0,099$)$; BX: baixa $(0,100$ a 0,299); MD: moderada (0,300 a 0,499); SB: substancial (0,500 a 0,699); MA: muito alta $(0,700$ a 0,999$)$; perfeita $(1,000)$.

No armazenamento na câmara controlada foi observado decréscimo na condutividade em todas as embalagens e, exceto para os diásporos acondicionados em malha de polietileno, o comportamento foi linear (Figura 3). Para os diásporos mantidos em ambiente de sala, este comportamento foi de $3^{\circ}$ grau, independentemente da embalagem. Exceto para os diásporos mantidos em lata, aqueles acondicionados nas outras embalagens apresentaram aumento na condutividade

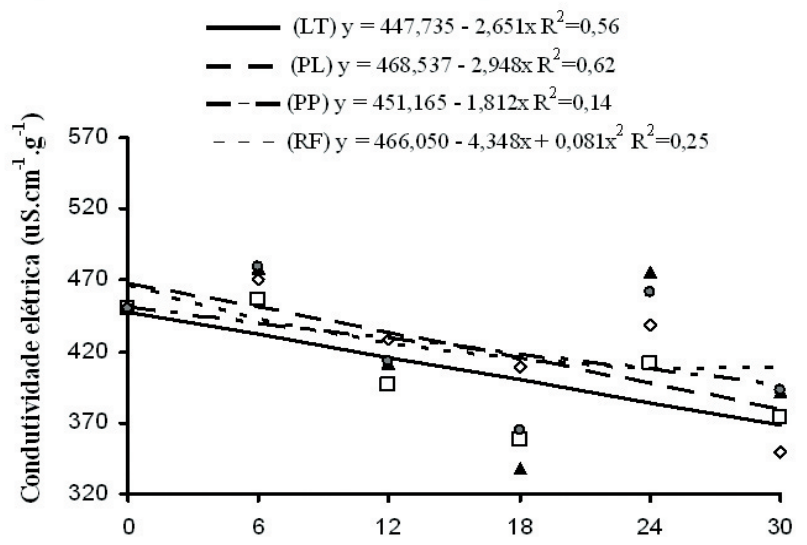

(A)

Período de armazenamento após seis e 18 meses e diminuição após 12 meses. Como os diásporos armazenados em câmara controlada se mantiveram viáveis até 24 ou 30 meses, dependendo do substrato, e aqueles mantidos no ambiente de sala perderam a viabilidade aos 18 meses, esperava-se que a condutividade aumentasse e isto não ocorreu. Para confirmar, os coeficientes de correlação entre estas variáveis, foram baixos e não significativos (Tabela 2).

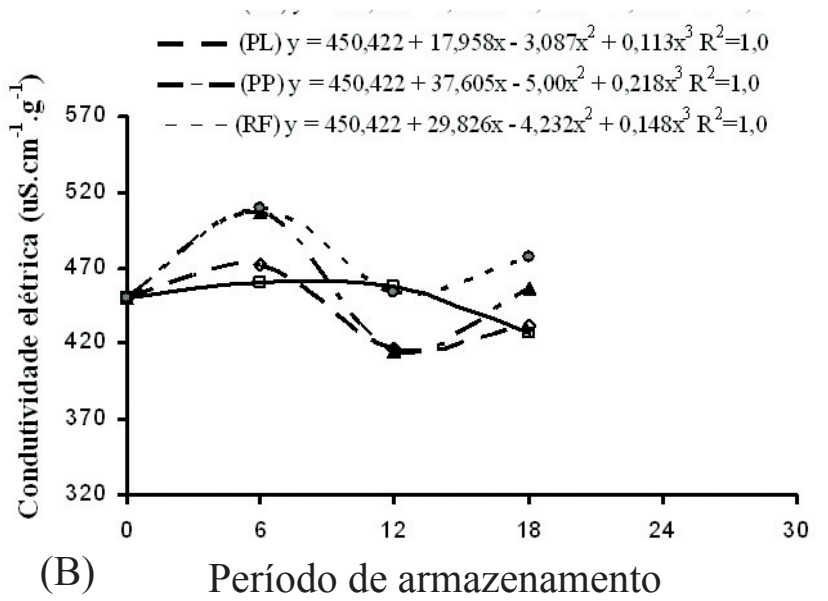

FIGURA 3. Variação da condutividade elétrica de diásporos de Myracrodruon urundeuva acondicionados em lata $(L T, \square)$ e em sacos de polietileno (PL, $)$, de papel (PP, $\Delta$ ), e de malha $(\mathrm{RF}, \bullet)$, em função do período de armazenamento em câmara controlada (A) e em ambiente de sala (B). Cuiabá, MT, 2003-2006. 
$\mathrm{O}$ fruto da aroeira exsuda um líquido de aspecto resinoso (Pacheco et al., 2006) o qual chegou, inclusive, a manchar as embalagens utilizadas. É provável que na análise inicial uma quantidade maior tenha sido liberada e, nas análises seguintes, parte deste líquido tenha ficado retida na superfície da embalagem, o que pode ter contribuído para a diminuição da condutividade. Ainda assim, valores registrados na literatura estão próximos dos aqui observados. Por outro lado, Duarte et al. (2000) observaram maior perda de eletrólitos com o aumento do período de armazenamento de diásporos de aroeira. Assim, novos estudos são necessários para melhor esclarecer este aspecto.

A variação da massa de 1000 diásporos de aroeira armazenados apresentou diferentes comportamentos, de acordo com o tipo de embalagem e com o ambiente de armazenamento (Figura 4). Assim ocorreram aumentos e diminuições alternadas ou consecutivas, de acordo com a embalagem. Desta forma, as embalagens podem ter propiciado maior ou menor retenção da resina o que, também, pode ter afetado a avaliação dessa característica. Duarte et al. (2000) registraram a diminuição desta variável com o armazenamento.

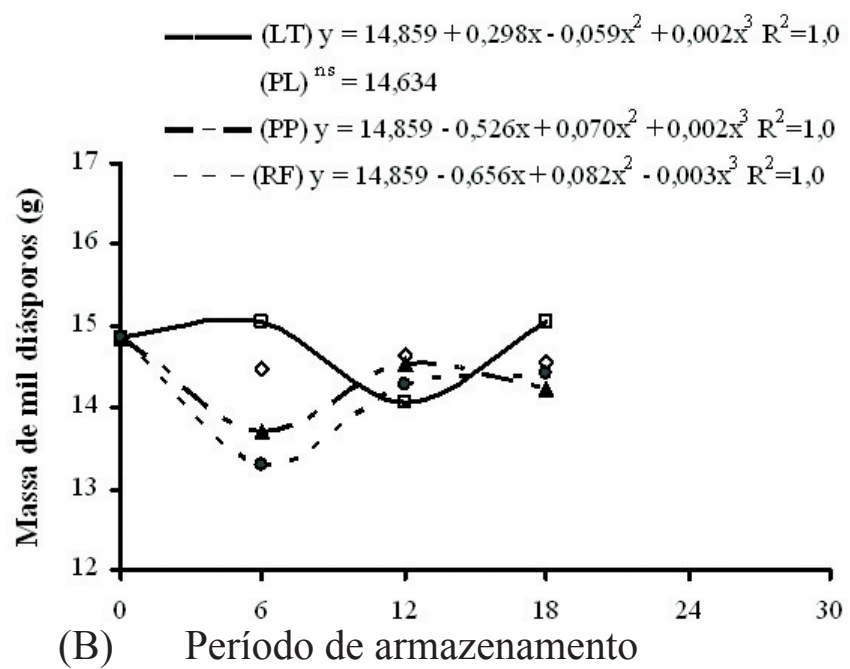

FIGURA 4. Variação da massa de mil diásporos de Myracrodruon urundeuva acondicionados em lata (LT, $\square$ ) e em sacos de polietileno $(\mathrm{PL}, \diamond)$, de papel $(\mathrm{PP}, \Delta)$ e de malha $(\mathrm{RF}, \bullet)$, em função do período de armazenamento em câmara controlada (A) e em ambiente de sala (B). (ns) regressão não significativa. Cuiabá, MT, 20032006.

Apesar da pequena dimensão dos diásporos de aroeira, a hipótese de que a variação da massa de mil diásporos poderia estar relacionada com a variação do teor de água, não se confirmou. As correlações entre esta variável com a germinação e com o vigor foram baixas e com a condutividade elétrica, baixa e negativa (Tabela 2).

\section{CONCLUSÕES}

Os diásporos de aroeira acondicionados em lata hermética ou em sacos de polietileno podem ser armazenados em ambiente controlado por condicionador de ar por, pelo menos, 30 meses.

Em ambiente de sala, com temperatura e umidade relativa variáveis, $\mathrm{o}$ acondicionamento deve ser em lata hermética e por período não superior a seis meses.

$\mathrm{Na}$ análise de diásporos de aroeira durante $\mathrm{o}$ armazenamento, o substrato afeta a germinação, mas não afeta o vigor.

Com a metodologia empregada, o teste de condutividade elétrica e a massa de mil diásporos não são adequados para avaliar a qualidade de diásporos de aroeira durante o armazenamento.

\section{REFERÊNCIAS}

ABDALA, L.; MORAES, M.L.T.; RECHIA, C.G.V.; GIORGINI, J.F.; SÁ, M.E.; POLIZELI, M. L.T.M. Biochemical traits useful for the determination of genetic variation in a natural population of Myracrodruon urundeuva. Pesquisa Agropecuária Brasileira, Brasília, v.37, n.7, 
p.909-916, 2002.

BAUDET, L.; VILLELA, F.A. Almacenamiento de semillas. In: BAUDET, L; PESKE, S. Semillas: ciencia y tecnología. Pelotas: Universidade Federal de Pelotas, 2005. p.259-288.

BRASIL. Ministério da Agricultura e Reforma Agrária. Regras para análise de sementes. Brasília: SNDA/DNDV/ CLAV, 1992. 365p.

CARNEIRO, J.G.A.; AGUIAR, I.B. Armazenamento de sementes. In: AGUIAR, I.B.; PIÑA-RODRIGUES, F.C.M.; FIGLIOLIA, M.B. (Ed.) Sementes florestais tropicais. Brasília: ABRATES, 1993. p.333-350.

DAL'COL LÚCIO, A.; FORTES, F.O.; STORCK, L.; CARGNELUTTI FILHO, A. Abordagem multivariada em análise de sementes de espécies florestais exóticas. Cerne, Lavras, v.12, n.1, p.27-37, 2006.

DORNELES, M.C.; RANAL, M.A.; SANTANA, D.G. Germinação de diásporos recém-colhidos de Myracrodruon urundeuva Allemão (Anacardiaceae) ocorrente no cerrado do Brasil Central. Revista Brasileira de Botânica, São Paulo, v.28, n.2, p.399-408, 2005.

DUARTE,E.F.; MORAIS,O.M.;NAKAGAWA, J.Avaliação da germinação de sementes de aroeira (Myracrodruon urundeuva (Engler) Fr. Allem.) Anacardiaceae, em diferentes substratos, com e sem exo e mesocarpo. In: CONGRESSO DA SOCIEDADE BOTÂNICA DE SÃO PAULO, XIII., 2000, São Paulo. Resumos... São Paulo: USP, 2000. Disponível em: <http://www.ib.usp.br/sbsp/congresso/fb.htm>. Acesso em: 12 fev. 2006.

FERREIRA, D.F. Análises estatísticas por meio do Sisvar para Windows versão 4.0. In: 45a REUNIÃO ANUAL DA REGIÃO BRASILEIRA DA SOCIEDADE INTERNACIONAL DE BIOMETRIA, 45., 2000, São Carlos, SP. Resumos... São Carlos: UFSCar, 2000. p.255258. Disponível em: <http://www.dex.ufla.br/ danielff/ softwares.htm>. Acesso em: 27 Mar. 2006.

FRAYHA, I.M.V.M. A germinação da aroeira-do-sertão (Myracrodruon urundeuva Fr. All.): armazenamento, viabilidade dos propágulos e variabilidade intrapopulacional na germinação. 1999. 84f. Dissertação (Mestrado em Ecologia, Conservação e Manejo da Vida Silvestre) - Instituto de Ciências Biológicas, Universidade Federal de Minas Gerais, Belo Horizonte, 1999.

MARCOS FILHO, J. Fisiologia de sementes de plantas cultivadas. Piracicaba: FEALQ, 2005. 495p.

MARQUES, M.A.; PAULA, R.C.; RODRIGUES, T.J.D. Diferenciação de lotes de sementes de Jacarandá-da-Bahia (Dalbergia nigra (Vell.) Fr.All. ex Benth.) pelo teste de germinação em laboratório e viveiro. Revista Brasileira de Sementes, Brasília, v.24, n.1, p.244-247, 2002.

MARTINS-NETTO, D.A.; FAIAD, M.G.R. Viabilidade e sanidade de sementes de espécies florestais. Revista Brasileira de Sementes, Brasília, v.17, n.1, p.75-80, 1995.

MEDEIROS, A.C.S.; CAVALLARI, D.A.N. Conservação de germoplasma de aroeira (Astronium urundeuva (Fr. All.) Engl.). I. Germinação de sementes após imersão em nitrogênio líquido $\left(-196^{\circ} \mathrm{C}\right)$. Revista Brasileira de Sementes, Brasília, v.14, n.1, p.73-75, 1992.

MEDEIROS, A.C.S.; PROBERT, R.J.; SADER, R.; SMITH, R.D. The moisture relations of seed longevity in Astronium urundeuva (Fr. All.) Engl. Seed Science and Technology, Zurich, v.26, n.2, p.289-298, 1998.

MEDEIROS, A.C.S.; SMITH, R.; PROBERT, R.; SADER, R. Comportamento fisiológico de sementes de aroeira (Myracrodruon urundeuva Fr. All.) em condições de armazenamento. Boletim de Pesquisa Florestal, Colombo, n.40, p.85-98, 2000.

PACHECO, M.V.; MATOS, V.P.; FERREIRA, R.L.C.; FELICIANO, A.L.P.; PINTO, K.M.S. Efeito de temperaturas e substratos na germinação de sementes de Myracrodruon urundeuva Fr. All. (Anacardiaceae). Revista Árvore, Viçosa, v.30, n.3, p.359-367, 2006.

PEREZ, S.C.J.G.A.; JARDIM, M.M. Viabilidade e vigor de sementes de paineira após armazenamento, condicionamento e estresses salino e térmico. Pesquisa Agropecuária Brasileira, Brasília, v.40, n.6, p.587-593, 2005.

PHARTYAL, S.S.; THAPLIYAL, R.C.; KOEDAM, N.; GODEFROID, S. Ex-situ conservation of rare and valuable forest tree species through seed-gene bank. Current Science, Bangalore, v.83, n.11, p.1351-1357, 2002.

PIÑA-RODRIGUES, F.C.M.; FIGLIOLIA, M.B.; PEIXOTO, M.C. Testes de qualidade. In: FERREIRA, A.G.; BORGHETTI, F. (Org.). Germinação: do básico ao aplicado. Porto Alegre: Artmed, 2004. p.283-297.

PONTES, C.A.; CORTE, V.B.; BORGES, E.E.L.; SILVA, A.G.; BORGES, R.C.G. Influência da temperatura de armazenamento na qualidade das sementes de Caesalpinia peltophoroides Benth. (sibipiruna). Revista Árvore, Viçosa, v.30, n.1, p.43-48, 2006.

SALOMÃO, A.N.; ALLEM, A.C. Polyembriony in an angiospermous tree of the Brazilian Cerrado and Caatinga vegetation. Acta Botânica Brasilica, São Paulo, v.15, n.3, p.369-378, 2001. 
SANTOS, S.R.G.; PAULA, R.C. Teste de condutividade elétrica para avaliação da qualidade fisiológica de sementes de Sebastiana commersoniana (Bail) Smith \& Downs Euphorbiaceae. Revista Brasileira de Sementes, Brasília, v.27, n.2, p.136-145, 2005.

SAUTU, A.; BASKIN, J.M.; BASKIN, C.C.; CONDIT, R. Studies on the seed biology of 100 native species of trees in a seasonal moist tropical forest, Panama, Central America. Forest Ecology and Management, Amsterdam, v.234, p.245-263, 2006.

SILVA, L.M.M.; RODRIGUES, T.J.D.; AGUIAR, I.B. Efeito da luz e da temperatura na germinação de sementes de aroeira (Myracrodruon urundeuva Allemão). Revista Árvore, Viçosa, v.26, n.6, p.691-697, 2002.

SIQUEIRA, A.C.M.F.; FIGLIOLIA, M.B. Maturação de sementes de Astronium urundeuva (Fr. All.). In: CONGRESSO BRASILEIRO DE SEMENTES, 5., 1987, Gramado, RS. Resumos... Brasília: ABRATES, 1987. p.152.

SOUZA, S.M.; PIRES, I.E.; LIMA, P.C.F. Efeito do tipo de embalagens e condições de armazenamento na preservação de sementes de aroeira (Astronium urundeuva Engl.). In: PESQUISA FLORESTAL NO NORDESTE SEMI-ÁRIDO: SEMENTES E MUDAS. Petrolina: EMBRAPA-CPATSA, 1980. p.25-30. (Boletim de Pesquisa, No. 2).

TEÓFILO, E.M.; SILVA, S.O.; BEZERRA, A.M.E.; MEDEIROS FILHO, S.; SILVA, F.D.B. Qualidade fisiológica de sementes de aroeira (Myracrodruon urundeuva ) em função do tipo de embalagem, ambiente e tempo de armazenamento. Revista Ciência Agronômica, Fortaleza, v.35, n.2, p.371-376, 2004.

THAPLIYAL, R.C.; CONNOR, K.F. Effects of accelerated ageing on viability, leachate exudation, and fatty acid content of Dalbergia sissoo Roxb. seeds. Seed Science and Technology, Zurich, v.25, v.2., p.311-319, 1997.

VIEIRA, R.D.; KRZYZANOWSKI, F.C. Teste de condutividade elétrica. In: KRZYZANOWSKI, F.C.; VIEIRA, R.D.; FRANÇA NETO, J.B. (Ed.). Vigor de sementes: conceitos e testes. Londrina, ABRATES, 1999. p.4.1-4.26. 